\title{
Broad-Spectrum Efficacy across Cognitive Domains by $\alpha 7$ Nicotinic Acetylcholine Receptor Agonism Correlates with Activation of ERK1/2 and CREB Phosphorylation Pathways
}

\author{
Robert S. Bitner, ${ }^{1}$ William H. Bunnelle, ${ }^{1}$ David J. Anderson, ${ }^{1}$ Clark A. Briggs, ${ }^{1}$ Jerry Buccafusco, ${ }^{2}$ Peter Curzon, ${ }^{1}$ \\ Michael W. Decker, ${ }^{1}$ Jennifer M. Frost, ${ }^{1}$ Jens Halvard Gronlien, ${ }^{1}$ Earl Gubbins, ${ }^{1}$ Jinhe Li, ${ }^{1}$ John Malysz, ${ }^{1}$ \\ Stella Markosyan, ${ }^{1}$ Kennan Marsh, ${ }^{1}$ Michael D. Meyer, ${ }^{1}$ Arthur L. Nikkel, ${ }^{1}$ Richard J. Radek, ${ }^{1}$ Holly M. Robb, ${ }^{1}$ \\ Daniel Timmermann, ${ }^{3}$ James P. Sullivan, ${ }^{1}$ and Murali Gopalakrishnan ${ }^{1}$ \\ ${ }^{1}$ Neuroscience Research, Global Pharmaceutical Research and Development, Abbott Laboratories, Abbott Park, Illinois 60064, ${ }^{2}$ Alzheimer's Research \\ Center, Medical College of Georgia, Augusta, Georgia 30912, and ${ }^{3}$ NeuroSearch A/S, DK-2750 Ballerup, Denmark
}

The $\alpha 7$ nicotinic acetylcholine receptor (nAChR) plays an important role in cognitive processes and may represent a drug target for treating cognitive deficits in neurodegenerative and psychiatric disorders. In the present study, we used a novel $\alpha 7 \mathrm{nAChR}$-selective agonist, 2-methyl-5-(6-phenyl-pyridazin-3-yl)-octahydro-pyrrolo[3,4-c]pyrrole (A-582941) to interrogate cognitive efficacy, as well as examine potential cellular mechanisms of cognition. Exhibiting high affinity to native rat $\left(K_{\mathrm{i}}=10.8 \mathrm{nM}\right)$ and human $\left(K_{\mathrm{i}}=16.7 \mathrm{nM}\right) \alpha 7$ nAChRs, A-582941 enhanced cognitive performance in behavioral assays including the monkey delayed matching-to-sample, rat social recognition, and mouse inhibitory avoidance models that capture domains of working memory, short-term recognition memory, and long-term memory consolidation, respectively. In addition, A-582941 normalized sensory gating deficits induced by the $\alpha 7 \mathrm{nAChR}$ antagonist methyllycaconitine in rats, and in DBA/2 mice that exhibit a natural sensory gating deficit. Examination of signaling pathways known to be involved in cognitive function revealed that $\alpha 7 \mathrm{nAChR}$ agonism increased extracellular-signal regulated kinase 1/2 (ERK1/2) phosphorylation in PC12 cells. Furthermore, increases in ERK1/2 and cAMP response element-binding protein (CREB) phosphorylation were observed in mouse cingulate cortex and/or hippocampus after acute A-582941 administration producing plasma concentrations in the range of $\alpha 7$ binding affinities and behavioral efficacious doses. The MEK inhibitor SL327 completely blocked $\alpha 7$ agonist-evoked ERK1/2 phosphorylation. Our results demonstrate that $\alpha 7 \mathrm{nAChR}$ agonism can lead to broad-spectrum efficacy in animal models at doses that enhance ERK1/2 and CREB phosphorylation/activation and may represent a mechanism that offers potential to improve cognitive deficits associated with neurodegenerative and psychiatric diseases, such as Alzheimer's disease and schizophrenia.

Key words: nicotinic acetylcholine receptor; $\alpha 7$ agonist; cognitive domains; ERK1/2; CREB; phosphorylation

\section{Introduction}

Cholinergic transmission, involving activation of the nicotinic acetylcholine receptor (nAChR) and muscarinic acetylcholine receptor, is recognized as an essential neurophysiological component in learning and memory formation (Bartus, 2000). This is supported by the observation that cholinergic neuron loss is a major etiological factor in neurodegenerative cognitive disorders such as Alzheimer's disease (AD) (Kasa et al., 1997). Whereas studies over the last 25 years have demonstrated that activation of both cholinergic receptors can lead to procognitive effects (Potter et al., 1999; Bartus, 2000; Fisher et al., 2003), more recently there

Received May 29, 2007; revised July 30, 2007; accepted Aug. 13, 2007.

We thank Dr. Daniel Bertrand for his input, and we acknowledge the contributions of Hilde Ween and Kirsten Thorin-Hagene.

Correspondence should be addressed to Dr. Robert S. Bitner, Department R4N5, Building AP9A, Abbott Laboratories, 100 Abbott Park Road, Abbott Park, IL 60064. E-mail: robert.s.bitner@abbott.com.

DOI:10.1523/JNEUROSCI.2444-07.2007

Copyright $\odot 2007$ Society for Neuroscience ～0270-6474/07/2710578-10\$15.00/0 has been a heightened interest in the role of the $\alpha 7 \mathrm{nAChR}$ subtype in cognitive function and pathophysiology.

The $\alpha 7 \mathrm{nAChR}$ is a homopentameric ligand-gated ion channel highly expressed in the hippocampus and cerebral cortex (Seguela et al., 1993). Hippocampal $\alpha 7 \mathrm{nAChRs} \mathrm{can} \mathrm{modulate} \mathrm{neurotransmit-}$ ter release from both GABAergic and glutamatergic terminals, as well as act postsynaptically to mediate excitatory input (Gray et al., 1996; Radcliffe et al., 1999). Antisense knock-down of $\alpha 7 \mathrm{nAChR}$ expression in rat hippocampus and cortex disrupts learning acquisition in the Morris water maze (Curzon et al., 2006). Studies examining $\alpha 7 \mathrm{nAChR}$ expression in $\mathrm{AD}$ brains have reported both decreased and increased expression, attributable to bidirectional changes in neurons and astrocytes, respectively (Court et al., 2001; Nordberg, 2001; Yu et al., 2005). The $\alpha 7 \mathrm{nAChR}$ has also been implicated in the pathogenesis of schizophrenia in which genetic linkage of the $\alpha 7 \mathrm{nAChR}$ gene (CHRNA7) is a predisposing etiological factor involving sensory gating deficits (Stassen et al., 2000; Gault et al., 2003). Similar to AD, reduced $\alpha 7 \mathrm{nAChR}$ expression has been observed in brains from schizophrenic patients (Freedman et al., 2000). Conversely, $\mathrm{AD}$ patients exhibit sensory gating deficits as seen 
in schizophrenia (Jessen et al., 2001). Together, these findings support the role of the $\alpha 7 \mathrm{nAChR}$ in cognitive processing and suggest that targeting this receptor subtype may be a viable approach for ameliorating cognitive deficits associated with neuropsychiatric and neurodegenerative diseases.

Nicotine, the prototypical nAChR agonist, is known to enhance cognition in both laboratory animals (Levin and Simon, 1998) and in humans, the latter including $\mathrm{AD}$ and schizophrenic patients (White and Levin, 1999; Rezvani and Levin, 2001; Harris et al., 2004; Levin et al., 2006). More recently, selective $\alpha 7$ agonists have been reported to improve cognitive function in animal models. ARR17779 reversed scopolamine-induced short-term memory impairment in the rat social recognition model (Van Kampen et al., 2004). PNU-282987 enhanced GABAergic synaptic activity and attenuated amphetamine-induced auditory gating deficits in rats (Hajos et al., 2005). The $\alpha 7 \mathrm{nAChR}$ partial agonist, SSR180711, increased synaptic hippocampal transmission, evoked $\mathrm{ACh}$ and dopamine release, and improved cognitive performance in mice (Biton et al., 2007; Pichat et al., 2007). Whereas these studies have provided evidence that selective $\alpha 7 \mathrm{nAChR}$ agonism can enhance cognitive performance, possibly involving changes in hippocampal synaptic plasticity, little is known regarding the underlying signaling pathways involved.

Compared with the $\alpha 4 \beta 2$ subtype, $\alpha 7$ has higher relative permeability for $\mathrm{Ca}^{2+}$ that raises the possibility that, in addition to ionotropic function, $\alpha 7 \mathrm{nAChRs}$ are associated with metabotropic activity coupled to calcium-regulated second-messenger signaling (Berg and Conroy, 2002). It may be hypothesized that a component of the procognitive activity associated with $\alpha 7 \mathrm{nAChRs}$ involves activation of signaling pathways required for cognitive processing such as the calcium-sensitive mitogen-activated protein kinase (MAPK) cascade. The role of the MAPK pathway, in particular activation/phosphorylation of extracellular-signal regulated kinase (ERK), is regarded as a key biochemical event in cognition through activation of cAMP response element-binding protein (CREB), a transcription factor linked to the formation of long-term memory (Adams and Sweatt, 2002). Studies have shown that pharmacological or molecular inhibition of ERK and/or CREB function leads to memory impairment, whereas genetic overexpression and activation contributes to memory enhancement (Selcher et al., 1999; Adams and Sweatt, 2002).

In this study, we sought to investigate the cognition efficacy spectrum of $\alpha 7 \mathrm{nAChR}$ agonism and underlying mechanisms at the level of MAPK and CREB pathways. First, using a novel subtype-selective $\alpha 7 \mathrm{nAChR}$ agonist, we examined the efficacy profile across an array of animal models representing different domains of cognitive function relevant to learning and memory impairments observed in $\mathrm{AD}$ and schizophrenia. Second, the effects of $\alpha 7$ agonism on cellular signaling involved in cognitive processing were investigated. Our studies demonstrate that selective $\alpha 7 \mathrm{nAChR}$ agonism improves performance across various domains of cognition that includes short-term working memory, recognition memory, long-term memory consolidation, and sensory gating preattention and that these effects correlate with activation of MAPK and CREB phosphorylation pathways in hippocampus and cingulate cortex.

\section{Materials and Methods}

Animals

Male Sprague Dawley rats (Charles River, Portage, MI), weighing 275$400 \mathrm{~g}$, and CD1 and DBA/2 mice (Charles River), weighing 20-30 g, were used. Animals were grouped housed in an American Association for Accreditation of Laboratory Animal Care (AAALAC)-approved facility at Abbott Laboratories in a temperature-regulated environment with lights on between 7:00 A.M. and 8:00 P.M. All experimental procedures involving animals were conducted under protocols approved by the $\mathrm{Ab}$ bott Laboratories Institutional Animal Care and Use Committee. In delayed matching-to-sample (DMTS) studies, young adult rhesus monkeys (Macaca mulatta) well trained ( $>100$ individual sessions) in the DMTS task were used. The monkeys were maintained on a $12 \mathrm{~h}$ light/dark cycle and were tested each weekday between 9:00 A.M. and 2:00 P.M. Room temperature and humidity were maintained at $72.0 \pm 1.0^{\circ} \mathrm{C}$ and $52.0 \pm$ $2.0 \%$, respectively. DMTS task procedures were reviewed and approved by the Medical College of Georgia Institutional Animal Care and Use Committee and are consistent with AAALAC guidelines.

\section{Chemicals}

2-Methyl-5-(6-phenyl-pyridazin-3-yl)-octahydro-pyrrolo[3,4-c]pyrrole (A-582941) and $\alpha$-[amino[(4-aminophenyl)thio]methylene]-2-(trifluoromethyl)benzene acetonitrile (SL327) were synthesized by Abbott Laboratories. Unless otherwise noted, all other reagents were obtained from Sigma (St. Louis, MO). Compounds were prepared in water or DMSO (SigmaAldrich, St. Louis, MO) as a 5 or $10 \mathrm{~mm}$ stock and protected from light, and serial dilutions were prepared in appropriate assay buffer just before use.

\section{Radioligand binding assays}

Binding of $\left[{ }^{3} \mathrm{H}\right]$ cytisine (Pabreza et al., 1991) and $\left[{ }^{3} \mathrm{H}\right]-(S, S)-2,2$ dimethyl-5-(6-phenyl-pyridazin-3-yl)-5-aza-2-azonia-bicyclo[2.2.1]heptane iodide $\left(\left[{ }^{3} \mathrm{H}\right] \mathrm{A}-585539\right)$ was performed using membrane fractions from rat brain (minus cerebellum) or human cortex. Briefly, frozen membranes were resuspended in $30 \mathrm{vol}$ of BSS-Tris buffer (in mM: $120 \mathrm{NaCl}$, $5 \mathrm{KCl}, 2 \mathrm{CaCl}_{2}, 2 \mathrm{MgCl}_{2}$, and 50 Tris-Cl, $\mathrm{pH} \mathrm{7.4,} 4^{\circ} \mathrm{C}$ ). Samples containing $100-200 \mu \mathrm{g}$ of protein and $0.75 \mathrm{~nm}\left[{ }^{3} \mathrm{H}\right]$ cytisine or $0.5 \mathrm{~nm}$ $\left[{ }^{3} \mathrm{H}\right] \mathrm{A} 585539$ were incubated in a final volume of $500 \mu \mathrm{l}$ for $75 \mathrm{~min}$ at $4^{\circ} \mathrm{C}$. Nonspecific binding was determined in the presence of $10 \mu \mathrm{M}(-)$ nicotine for $\left[{ }^{3} \mathrm{H}\right.$ ] cytisine or $10 \mu \mathrm{M}$ methyllycaconitine for $\left[{ }^{3} \mathrm{H}\right] \mathrm{A}-585539$ binding. $\left[{ }^{3} \mathrm{H}\right]$ Epibatidine binding was performed using membranes isolated from IMR32 cells. Bound radioactivity was isolated by vacuum filtration onto prewetted glass fiber filter plates (Millipore, Bedford, MA) using a 96-well filtration apparatus (PerkinElmer Life and Analytical Sciences, Boston, MA) and was then rapidly rinsed with $2 \mathrm{ml}$ of ice-cold BSS buffer (in mм: $120 \mathrm{NaCl}, 5 \mathrm{KCl}, 2 \mathrm{CaCl}_{2}$, and $2 \mathrm{MgCl}_{2}$ ). Packard MicroScint-20 scintillation mixture $(40 \mu \mathrm{l})$ was added to each well, and radioactivity was determined using a Packard TopCount instrument.

\section{Electrophysiology}

Xenopus laevis oocytes were prepared for electrophysiological experiments as described previously (Briggs and McKenna, 1998). Briefly, three to four lobes from ovaries of female adult $X$. laevis were removed, manually defolliculated after being treated with collagenase type $1 \mathrm{~A}(2 \mathrm{mg} / 1$ $\mathrm{ml}$ of $\mathrm{Ca}^{2+}$-free Barth's solution) for $1.5-2 \mathrm{~h}$ at $\sim 18^{\circ} \mathrm{C}$ under constant agitation, and used for injections $1-5 \mathrm{~d}$ after preparation. Low $\mathrm{Ca}^{2+}$ Barth's solution contained $90 \mathrm{~mm} \mathrm{NaCl}, 1.0 \mathrm{~mm} \mathrm{KCl}, 0.66 \mathrm{~mm} \mathrm{NaNO}$, $2.4 \mathrm{~mm} \mathrm{NaHCO}_{3}, 10 \mathrm{~mm}$ HEPES, $2.5 \mathrm{~mm}$ Na-pyruvate, $0.82 \mathrm{~mm} \mathrm{MgCl}_{2}$, and $0.5 \% \mathrm{v} / \mathrm{v}$ penicillin-streptomycin solution (P0781; Sigma), $\mathrm{pH} 7.55$. The oocytes were injected with $\sim 20-25$ ng of human $\alpha 7$ nAChR cRNA, kept at $18^{\circ} \mathrm{C}$ in a humidified incubator in modified Barth's solution (90 mм NaCl, $1.0 \mathrm{~mm} \mathrm{KCl,} 0.66 \mathrm{~mm} \mathrm{NaNO}_{3}, 2.4 \mathrm{~mm} \mathrm{NaHCO}_{3}, 10 \mathrm{~mm}$ HEPES, $2.5 \mathrm{~mm} \mathrm{Na-pyruvate,} 0.74 \mathrm{~mm} \mathrm{CaCl}_{2}, 0.82 \mathrm{~mm} \mathrm{MgCl}_{2}$, and $0.5 \%$ v/v penicillin-streptomycin solution, $\mathrm{pH} 7.55$ ), and used 2-7 d after injection. Responses were measured using two-electrode voltage-clamp potential and parallel oocytes electrophysiology test stations technology (Trumbull et al., 2003). During recordings, the oocytes were bathed in $\mathrm{Ba}^{2+}$-OR2 solution (in mM: $90 \mathrm{NaCl}, 2.5 \mathrm{KCl}, 2.5 \mathrm{BaCl}_{2}, 1.0 \mathrm{MgCl}_{2}, 5.0$ HEPES, and 0.0005 atropine, $\mathrm{pH} 7.4)$. All experiments were done at room temperature $\left(\sim 20^{\circ} \mathrm{C}\right)$, with a holding potential of $-60 \mathrm{mV}$. Agonist responses were measured as the compound-induced peak (maximal) inward current relative to the baseline holding current and normalized to the ACh response determined in the same oocyte. Concentration-response parameters were determined using the nonlinear curve fitting in GraphPad (San Diego, CA) Prism and the built-in variable slope sigmoidal curve (Hill equation); fitting parameters were not constrained except that the bottom of the curve was set equal to zero. 
$\mathrm{Ca}^{2+}$ flux assays

IMR32 cells were obtained from American Type Culture Collection (Manassas, VA) and maintained using their specified procedures. HEK-293 cell lines stably expressing human $\alpha 4 \beta 2, \alpha 3 \beta 4$, and $\alpha 4 \beta 4 \mathrm{nAChRs}$ were maintained using standard procedures. Agonist-induced $\mathrm{Ca}^{2+}$ dynamics were measured using Fluo-4/AM to detect intracellular $\mathrm{Ca}^{2+}$ in conjunction with a fluorescence imaging plate reader (FLIPR) interfaced with a personal computer and equipped with an argon laser and a CCD camera (Molecular Devices, Sunnyvale, CA) to capture the fluorescence changes. The cell-permeant acetoxymethyl ester form of Fluo- 4 was prepared to a concentration of $1 \mathrm{~mm}$. The dye was then diluted to a final concentration of $2 \mu \mathrm{M}$ in growth medium and placed on the cells for $\sim 90 \mathrm{~min}$ at room temperature. Poly-D-lysine-coated black-walled 96-well plates with adherent cells were used to reduce light scattering. The unincorporated dye was removed from the cells by washing with assay buffer containing (in mM) $140 \mathrm{~N}$-methyl D-glucamine, $5 \mathrm{KCl}, 1 \mathrm{MgCl}_{2}, 10 \mathrm{CaCl}_{2}$, and 10 HEPES, pH 7.4. After addition of various concentrations of A-582941, the $\mathrm{Ca}^{2+}$ dynamics were measured in the FLIPR. The percentage maximal intensity was normalized to responses induced by $100 \mu \mathrm{M}$ (-)-nicotine, applied as reference control to each plate.

\section{ERK phosphorylation in PC12 cells}

Activation of native $\alpha 7 \mathrm{nAChR}$ signaling in rat PC12 cells was assessed by measurement of the stimulation of ERK phosphorylation. Briefly, PC12 cells obtained from American Type Culture Collection were cultured in poly-D-lysine-coated 96-well plates. Twenty-four hours before experiments, culture medium was replaced with unsupplemented F12K to reduce the basal level of ERK phosphorylation. The effects of agonist stimulation on ERK phosphorylation were measured at $37^{\circ} \mathrm{C}$ in $50 \mu \mathrm{l}$ of HBSS containing the $\alpha 7$ nAChR-positive allosteric modulator PNU-120596. Because $\alpha 7 \mathrm{nAChRs}$ rapidly desensitize on activation, agonist-evoked responses are not detectable by conventional methods that do not measure such rapid effects. However, when an $\alpha 7$-selective-positive allosteric modulator such as PNU-120596, which slows down receptor desensitization, is included, the response can be easily measured. After $10 \mathrm{~min}$ preincubation with $3 \mu \mathrm{M}$ PNU-120596, $50 \mu$ l of agonist in HBSS was added an additional $7 \mathrm{~min}$ incubation. Activity was terminated by transferring the incubation plate to ice, aspirating the medium, and lysing the cells on ice for 15 min with $5 \mu$ l of Insect Cell Lysis Buffer (PharMingen, San Diego, CA) containing 1\% sodium deoxycholate, $0.1 \%$ sodium dodecylsulphate, $1 \mathrm{~mm}$ sodium orthovanadate, $1 \%$ protease inhibitor mixture (Sigma), and $100 \mathrm{U} / \mathrm{ml}$ benzonase (Novagen, Madison, WI). Samples were stored at $-80^{\circ} \mathrm{C}$ before assay of total ERK and phospho-ERK by Western blot and fluorescence readout. Primary antibodies for ERK1/2 and diphosphorylated ERK1/2 were obtained from Cell Signaling Technology (Danvers, MA) and Sigma, respectively. Cyclophilin A antibody (Ab) was from Upstate Biotechnology (Lake Placid, NY). Secondary antibodies were fluorescently labeled with Alexafluor-680 (Invitrogen, Carlsbad, CA) or IRDye800 (Rockland Immunochemicals, Gilbertsville, $\mathrm{PA})$. Signals were measured by the Li-Cor (Lincoln, NE) Odyssey Infrared Imaging System.

\section{Immunohistochemical assessment of ERK1/2 and \\ CREB phosphorylation}

Mice received A-582941 (0.01, 1.0, $1.0 \mu \mathrm{mol} / \mathrm{kg}$, i.p.) for examining dose-dependent changes in ERK1/2 and CREB phosphorylation. Other mice were pretreated with the MAPK kinase (MEK) inhibitor (ERK1/2 phosphorylation blocker) SL327 (structural analog of UO126; $300 \mu \mathrm{mol} /$ kg, i.p.) (Favata et al., 1998) or vehicle (normal saline used for A-582941; DMSO used for SL327) and 15 min later were challenged with A-582941 ( $1 \mu \mathrm{mol} / \mathrm{kg}$, s.c.) or vehicle (saline). Fifteen minutes after the A-582941 (or vehicle) challenge, all mice were anesthetized and perfused through the aorta with normal saline followed by $10 \%$ formalin for immunohistochemical assessment of ERK1/2 and CREB phosphorylation in the cingulate cortex and/or hippocampus. After perfusion, brains were removed, postfixed in $20 \%$ sucrose-PBS overnight, subsequently cut on a cryostat (40 $\mu \mathrm{m}$ coronal sections), and collected as free-floating sections in PBS. Sections were then immunostained using a three-step ABCperoxidase technique beginning with a $30 \mathrm{~min}$ incubation with blocking serum. Sections were next incubated with either anti-phospho-ERK1/2 (mouse monoclonal IgG, 1:500; Cell Signaling Technology) or CREB (rabbit monoclonal IgG, 1:1000; Cell Signaling Technology) Ab for $48 \mathrm{~h}$ at $4^{\circ} \mathrm{C}$, washed with PBS, and incubated for $1 \mathrm{~h}$ with either biotinylated secondary anti-mouse or anti-sheep Ab solution (1:200). Finally, sections were washed in PBS, incubated with ABC reagent (Vector Laboratories, Burlingame, CA), and developed in a peroxidase substrate solution. Four to six serial sections from each animal were mounted, coverslipped, examined, and photographed with a light microscope (DMRB; Leica, Bannockburn, IL). A single section was then chosen on the basis of optimal immunoreactivity and anatomical similarity for immunoquantification, in which the experimenter was blind to treatment conditions. Both pERK and pCREB immunoreactivity in the cingulate cortex and hippocampus were quantified using an image analysis system (Leica Quantimet 500) that determined number and/or area of peroxidase substrate-positive-stained neurons from digitized photomicrographs according to a pixel gray level empirically determined before analysis.

\section{Blood plasma and brain concentrations}

For the determination of plasma and brain concentrations of the parent compound, naive rat or mouse were dosed with the compounds intraperitoneally and killed at various time points after dosing. For the determination of plasma concentrations, blood was collected into heparinized tubes and centrifuged, and the separated plasma was frozen at $-20^{\circ} \mathrm{C}$ until analysis. For the determination of brain concentrations, animals were decapitated at the various time points, and the brains were immediately removed and rapidly freed from blood vessels as much as possible. The resulting brain tissues were immediately frozen at $-20^{\circ} \mathrm{C}$, weighed, and homogenized, and the homogenate was stored at $-20^{\circ} \mathrm{C}$. For analysis, compounds were extracted from the samples via liquid-liquid extraction and quantified by liquid chromatography/mass spectroscopy.

\section{Delayed matching to sample titration}

Studies were conducted in young male rhesus monkeys that were initially trained in the DMTS procedure (Buccafusco et al., 2002). Using a touchsensitive screen in the animals' home cage, trial initiation consisted of presentation of one of three colored stimuli (red, blue, or yellow rectangles) that remained in view (sample stimuli) until touched by the subject. After a delay interval, two choice rectangles were presented, one being the previous sample stimulus, in which correct (matching) choice-touch to the sample stimuli was food reinforced. For standard DMTS testing, the duration for each delay interval was adjusted for each subject until three levels of performance accuracy were approximated: zero delay interval (85-100\% of trials answered correctly); short delay interval (75-84\% correct); medium delay interval (65-74\% correct); and long delay interval (55-64\% correct). The titration version of the DMTS task used in the present studies required the animals to perform a 96-trial session that began with a $0 \mathrm{~s}$ delay interval (Buccafusco et al., 2002). If the trial was answered correctly, a $1 \mathrm{~s}$ delay interval was presented during the next trial presented. The $1 \mathrm{~s}$ incremental progression was maintained until the subject made an incorrect match. The delay interval for the trial after an incorrect match was always decreased by $1 \mathrm{~s}$. After an incorrect match, if the next trial was answered correctly, the subsequent trial presented a delay interval $1 \mathrm{~s}$ longer in duration. Dependent variables included the overall percentage of trials answered correctly, the number of trials to reach the maximal delay interval attained, and the maximum and average delay interval attained (in seconds). Subjects received A-582941 (4, 14, 40 $\mathrm{nmol} / \mathrm{kg}$, i.m.) or saline $30 \mathrm{~min}$ before DMTS testing.

\section{Inhibitory avoidance}

The inhibitory avoidance task involves the uses of a two-compartment step through apparatus that measures the animal's ability to remember a brief noxious stimulus (footshock) and is considered a measure of onetrial learning, memory consolidation. Briefly, mice were placed in a lighted compartment of the apparatus in which the latency to enter into the preferred dark compartment was recorded. Entry into a dark compartment resulted in the immediate delivery of a mild footshock $(0.1 \mathrm{~mA}$, $1 \mathrm{~s}$ duration). Retention testing was conducted $24 \mathrm{~h}$ later with the animal again placed in the lighted compartment in which its latency to reenter 
the dark side of the apparatus was measured (no shock). Increasing retention latency was regarded as an index of memory consolidation.

\section{Social recognition}

The social recognition test measures short-term memory on the basis of olfactory cues and depends on the hippocampus. Adult (2-4 month) rats were allowed to interact with a juvenile rat for a 5 min interaction trial (T1) in which the adult exhibits behaviors that included close following, grooming, and/or sniffing of the juvenile for as much as $40-50 \%$ of the trial duration. The juvenile rat was then removed, and the adult rat was immediately administered A-582941 (0.01, 0.1, $1.0 \mu \mathrm{mol} / \mathrm{kg}$, i.p.). A second 5 min recognition trial (T2) was conducted 120 min later in which interactive behavior of the adult rat was again monitored. If recognition memory was lost over the $120 \mathrm{~min}$ interval between trials, the interactive behavior would be similar for the two trials; however, if memory was retained, the ratio (T2:T1) would decline (i.e., deceasing $\mathrm{T} 2: \mathrm{T} 1$ ratio regarded as an index of improved short-term recognition memory).

\section{N40 auditory sensory gating}

N40 measurements in rat. Under pentobarbital anesthesia $(50 \mathrm{mg} / \mathrm{kg}$, i.p.), stainless steel EEG recording electrodes were implanted in rats over the parietal cortices [anteroposterior (AP), $-3.0 \mathrm{~mm}$; lateral (L), $4.0 \mathrm{~mm}$ from bregma]. A reference electrode was placed over the cerebellum 11 $\mathrm{mm}$ posterior to bregma. In addition, a 25 gauge guide cannula for intracerebroventricular injection of the $\alpha 7$ antagonist methyllycaconitine citrate (MLA) was implanted at a location of AP $-0.8, \mathrm{~L} 1.5$, and depth of $3.5 \mathrm{~mm}$ from the surface of the skull. The miniature electrical connector and guide cannula were affixed to the skull with dental cement.

Auditory-evoked potentials were recorded from unanesthetized, freely moving rats inside sound-attenuating chambers (Med Associates, St. Albans, VT). AC differential amplifiers (Grass Instrument Division, AstroMed Incorporated, West Warwick, RI) and a computer-based acquisition system (Datawave Incorporated, Berthoud, CO) were used to condition, acquire, and analyze EEG bio-signals. Auditory-evoked potentials were generated by presentation of 120 sets of paired white noise bursts $(65 \mathrm{~dB})$ of $5 \mathrm{~ms}$ duration from a speaker within the recording chamber at a distance of $\sim 20 \mathrm{~cm}$ from the rat. The first auditory stimulus of the pair, or conditioning stimulus (C), was followed $0.5 \mathrm{~s}$ later by the second auditory stimulus, also referred to as the test stimulus (T). The length of time between stimulus pairs, or interstimulus interval, was $20 \mathrm{~s}$. Using EEG data acquisition software (Neuroscan Incorporated, El Paso, TX), N40 amplitude was determined for both the averaged conditioning (CAMP) and test (TAMP) evoked potentials, and a ratio (T:C ratio) was derived between the two responses by dividing the test amplitude by the conditioning amplitude. In a crossover design, four treatments were given on separate days, with at least $48 \mathrm{~h}$ between treatments and each treatment consisting of two injections: first, an intracerebroventricular injection of either PBS $(5 \mu \mathrm{l})$ or MLA $(30 \mu \mathrm{g} / 5 \mu \mathrm{l})$, and $10 \mathrm{~min}$ later, an intraperitoneal injection with either saline $(1 \mathrm{ml} / \mathrm{kg})$ or A-582941 $(10.0 \mu \mathrm{mol} / \mathrm{kg}$, i.p.). Five to $10 \mathrm{~min}$ after the second injection, the rats were placed into isolation chambers for recording of sensory gating evoked potentials.

N40 measurements in DBA/2 mouse. Male DBA/2 mice were anesthetized with a solution of $2.8 \%$ ketamine, $0.28 \%$ xylazine, and $0.05 \%$ acepromazine (Sigma) and stereotaxically implanted with tripolar stainless steel wire electrodes (Plastics One, Roanoke, VA) for EEG recordings in the CA3 region of the hippocampus. The procedure to obtain auditory-evoked potentials was similar to those described for rat (above). Freely moving mice were recorded in acoustically isolated chambers (Med Associates). Auditory-evoked potentials were generated by presentation of 120 sets of paired white noise bursts ( $5 \mathrm{~ms}$ duration, $65 \mathrm{~dB}$ ) in which $\mathrm{C}$ was followed $0.5 \mathrm{~s}$ later by the $\mathrm{T}$. The length of time between stimulus pairs for mouse was $15 \mathrm{~s}$ instead of $20 \mathrm{~s}$ used for rat. Data acquisition software (Neuroscan Incorporated) recorded EEG signals $100 \mathrm{~ms}$ before and for $900 \mathrm{~ms}$ after the initial conditioning stimulus. N40 amplitude was determined for both the averaged CAMP and TAMP evoked potentials, and the T:C ratio was derived. Drugs were administered immediately before mice were placed into the recording chambers and initiation of auditory-evoked potential recording. Recording of paired auditory-evoked potentials continued for $30 \mathrm{~min}$ after the record- ings began. For every experiment, each mouse was administered all treatments including a control vehicle in random order on separate days with at least $72 \mathrm{~h}$ between treatments. This within-subjects design allowed each mouse to serve as its own control.

\section{Data analysis}

Data are presented as means \pm SEM with $95 \%$ confidence intervals (c.i.). Significant differences between group means were assessed by ANOVA followed by Fisher's protected least-squares difference post hoc analyses. A $p$ value $<0.05$ was considered statistically significant. In radioligand binding assays, the $\mathrm{IC}_{50}$ values were determined by nonlinear regression in Microsoft (Redmond, WA) Excel. $K_{\mathrm{i}}$ values were calculated from the $\mathrm{IC}_{50}$ using the Cheng-Prusoff equation, in which $K_{\mathrm{i}}=\mathrm{IC}_{50} /(1+[\mathrm{li}-$ gand $\left.] / K_{\mathrm{D}}\right)$. In electrophysiology and fluorescence-based assays, concentration-response parameters were determined using the nonlinear curve fitting in GraphPad Prism.

\section{Results}

\section{A-582941 is a selective $\alpha 7 \mathrm{nAChR}$ agonist}

Selective $\alpha 7 \mathrm{nAChR}$ agonists have been reported from diverse chemical classes. Initially, disclosed compounds, primarily from quinuclidine series, showed poor CNS penetration and thus were not ideal for in vivo validation studies. Accordingly, our lead optimization efforts and structure activity relationship studies focused on identification of compounds with excellent CNS penetration and pharmacokinetic properties of which A-582941 is a prototype that emerged from a biaryldiamine series [Basha A, Bunnelle WH, Dart MJ, Gallagher ME, Ji J, Li T, Pace JM, Ryther KB, Tietje KR, Mortell KH, Nersesian DL, Schrimpf MR (2005) U.S. Patent Publication US2005/0101602A1] (Fig. 1A).

\section{Radioligand binding}

Radioligand binding studies were used to assess selectivity of interactions of A-582941 at $\alpha 7 \mathrm{nAChRs}$ (Fig. $1 B$ ). We used $\left[{ }^{3} \mathrm{H}\right] \mathrm{A}-$ 585539 , a novel $\alpha 7 \mathrm{nAChR}$ agonist radioligand with pharmacological properties similar to that of $\left[{ }^{3} \mathrm{H}\right]$ MLA but, in addition, enables measurement of binding interactions at both rodent and human brain. In rat brain, A-582491 displaced the binding $\alpha 7$ nAChR agonist, [ $\left.{ }^{3} \mathrm{H}\right] \mathrm{A}-585539$ with a $K_{\mathrm{i}}$ value of $10.8 \mathrm{~nm}(95 \%$ c.i., $\left.6.2-19 \mathrm{nM} ; n_{\mathrm{H}}=1.1 ; n=9\right)$. Similar affinities were observed for displacement of binding to human frontal cortex membranes $\left[K_{\mathrm{i}}=16.7 \mathrm{nM}\left(95 \%\right.\right.$ c.i., $\left.\left.13-22 \mathrm{nM} ; n_{\mathrm{H}}=1.1 ; n=6\right)\right]$. In contrast, A-582941 was substantially weaker in displacing binding of $\left[{ }^{3} \mathrm{H}\right]$ cytisine to rat brain membranes $\left(K_{\mathrm{i}}>100 \mu \mathrm{M} ; n=4\right)$, $\left[{ }^{3} \mathrm{H}\right]$ epibatidine to IMR32 neuroblastoma $\left(K_{\mathrm{i}}=4.66 \mu \mathrm{M} ; n=3\right)$, or $\left[{ }^{125} \mathrm{I}\right] \alpha$-bungarotoxin to TE-671 cells $\left(K_{\mathrm{i}}>100 \mu \mathrm{M}\right)$, indicative of diminished interactions with $\alpha 4, \alpha 3$, and $\alpha 1$ subunitcontaining $\mathrm{nAChRs}$, respectively.

A-582941 was further evaluated in a radioligand binding screen panel containing representatives of multiple G-protein-coupled receptors and ligand- and voltage-gated ion channel binding sites at CEREP (Redmond, WA; receptor binding and enzyme profile). A-582941 $(10 \mu \mathrm{M})$ did not show significant displacement of binding of $>75$ targets with the exception of $5-\mathrm{HT}_{3}$ receptors in which it displaced $\left[{ }^{3} \mathrm{H}\right]$-BRL 43694 (granisetron) binding $(>85 \%$ at $10 \mu \mathrm{M})$. Additional examination of the concentration-response for $5-\mathrm{HT}_{3}$ binding inhibition revealed $K_{\mathrm{i}}=154 \mathrm{nM}\left(n_{\mathrm{H}}=1.8\right), \sim 15$-fold higher than the $K_{\mathrm{i}}$ at $\alpha 7 \mathrm{nAChRs}$. No inhibition of acetylcholinesterase $\left(\mathrm{IC}_{50}>10 \mu \mathrm{M}\right)$ or to muscarinic receptors $\left(\left[{ }^{3} \mathrm{H}\right] \mathrm{QNB}\right.$ binding; $\left.K_{\mathrm{i}}>100 \mu \mathrm{M}\right)$ were observed.

\section{Functional activity}

In Xenopus oocytes expressing human $\alpha 7$ nAChRs, A-582941 activated ionic currents in a concentration-dependent manner. Agonist responses were measured as the compound-induced 
peak (maximal) inward current relative to the baseline holding current and normalized to the ACh response determined in the same oocytes. The responses evoked by A-582941 were abolished in the presence of $10 \mathrm{~nm}$ MLA and were reversible on washout (Fig. 1C). Analysis of peak A-582941-evoked currents showed a maximal efficacy of $52.10 \%$ ( $95 \%$ c.i., $48.46-$ $55.75 \%)$ relative to $\mathrm{ACh}$ and $\mathrm{EC}_{50}$ value of $4.26 \mu \mathrm{M}\left(-\log \mathrm{EC}_{50}=5.37\right.$; 95\% c.i., 5.27-5.47; $n_{\mathrm{H}}=1.28$ ) (Fig. $1 D$ ). Comparable efficacy and potency was also noted at the human $\alpha 7 \mathrm{nAChRs}$ expressed in GH4C1 cells (efficacy, 58.5\%; $\mathrm{EC}_{50}=7.93$ $\mu \mathrm{M})$. At the rat $\alpha 7 \mathrm{nAChRs}$ expressed in oocytes, A-582941-evoked currents showed a maximal efficacy of $59.61 \%$ (95\% c.i., 54.63-64.59\%) relative to ACh and an $\mathrm{EC}_{50}$ value of $2.45 \mu \mathrm{M}\left(-\log \mathrm{EC}_{50}\right.$ $=5.61 ; 95 \%$ c.i., $\left.5.74-5.48 ; n_{\mathrm{H}}=1.38\right)$.

Functional selectivity across other nAChR subtypes was evaluated using FLIPR-based $\mathrm{Ca}^{2+}$ imaging studies in IMR32 neuroblastomas and in transfected cell lines. At concentrations at or above the $\alpha 7$ nAChR EC 50 value, A-582941 had little agonist effect on other $\mathrm{nAChR}$ subunits including $\alpha 4 \beta 2\left(\mathrm{EC}_{50}>100,000 \mathrm{nM}\right.$; maximal efficacy, $2.3 \pm 0.4 \%), \alpha 4 \beta 4$ subunits $\left(\mathrm{EC}_{50}\right.$ $>100,000 \mathrm{~nm}$; maximal efficacy, $1.9 \pm$ $0.4 \%), \alpha 3 \beta 4$ subunits $\left(\mathrm{EC}_{50}>100,000 \mathrm{nM}\right.$; maximal efficacy, $2.5 \pm 0.8 \%$ ), and the native $\alpha 3^{*}$ expressed by IMR32 cells $\left(\mathrm{EC}_{50}>\right.$ 100,000 nM; efficacy $3.5 \pm 0.9 \%$ ).

\section{Efficacy in models of learning and memory}

The in vivo efficacy profile of A-582941 was examined across a set of in vivo models, thought to capture various domains of memory processing including short-term memory (recognition memory and visual working memory) and long-term memory (memory consolidation and recall). In initial experiments, it was demonstrated that A-582941 exhibited excellent CNS penetration in rodents. For example, administration of A-582941 ( $1 \mu \mathrm{mol} / \mathrm{kg}$, i.p.) in mouse produced maximal levels in brain (286 ng/g at $0.33 \mathrm{~h}$ ) that were 11 -fold higher than the plasma $C_{\max }(26 \mathrm{ng} / \mathrm{ml}$ at $0.25 \mathrm{~h})$. This distribution ratio was maintained over an $8 \mathrm{~h}$ period, as drug cleared from brain and plasma with $t_{1 / 2}=2.5-3.2 \mathrm{~h}$. Similarly, in rat, A-582941 partitions with approximate sixfold higher levels in brain versus plasma after intraperitoneal dosing at 2-20 $\mu \mathrm{mol} / \mathrm{kg}$. Over this dose range, linear pharmacokinetics was observed, with brain $C_{\max }$ (normalized to a 1 $\mu \mathrm{mol} / \mathrm{kg}$ dose) averaging $363 \mathrm{ng} / \mathrm{g}$ and maximum plasma levels of 62 $\mathrm{ng} / \mathrm{ml}$.

\section{Short-term memory}

To determine the effects of $\alpha 7$ agonism on short-term working memory, A-582941 was evaluated in the monkey DMTS test us-
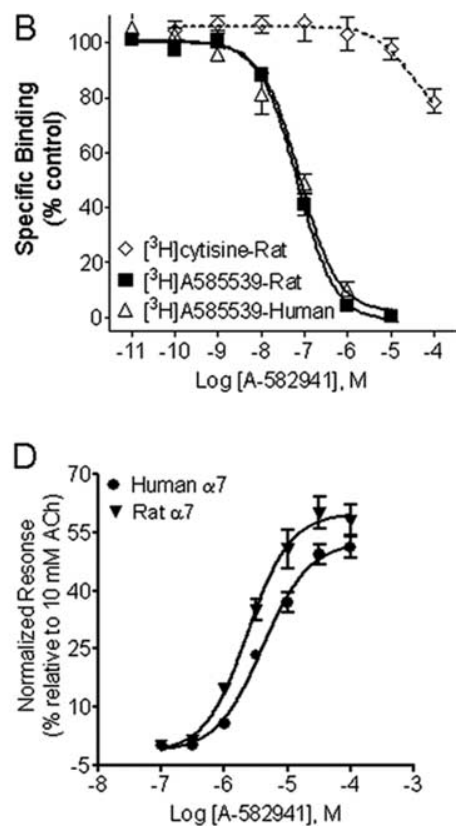

Figure 1. In vitro pharmacological properties of A-582941. $\boldsymbol{A}$, Structure of A-582941. $\boldsymbol{B}$, Displacement of $\left[{ }^{3} \mathrm{H}\right] \mathrm{A}-585539$ and $\left[{ }^{3} \mathrm{H}\right]$ cytisine binding to rat brain membranes by A-582941. C, Current traces showing activation of human $\alpha 7 \mathrm{nAChRs}$ expressed in Xenopus 0ocytes by ACh (top) and A-582941 (bottom). After preincubation with methyllycaconitine (MLA; $10 \mathrm{~nm}, 5 \mathrm{~min}$ ), current responses to both $A-582941$ and $A C h$ were abolished. Responses returned to control levels on washout. $\boldsymbol{D}$, Concentrationresponse data (mean \pm SEM) are shown for A-582941 as agonist at human and rat $\alpha 7$ nAChR expressed in Xenopus 00cytes. The $\mathrm{EC}_{50}$ and percentage maximal efficacy values are summarized in Results.
A

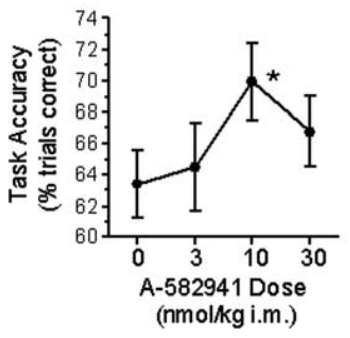

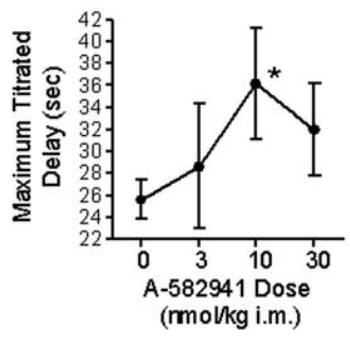

B

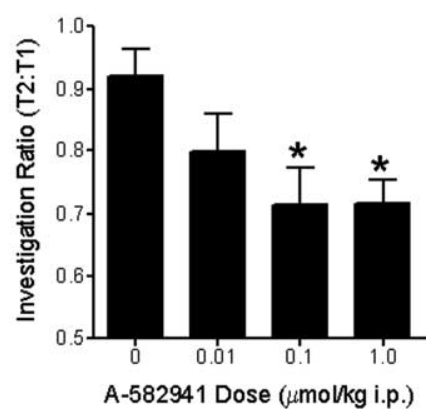

Figure 2. Efficacy profile in short-term memory models. $\boldsymbol{A}$, Improvements in DTMS task performance using a titration version by adult rhesus monkeys after administration of A-582941 (3, 10, and $30 \mathrm{nmol} / \mathrm{kg}$, i.m.). Task accuracy and the maximal delay interval titrated derived from the titrating version of the DMTS task is plotted as a function of dose $\left({ }^{*} p<0.05\right.$ vs vehicle-treated controls; $n=6$ per treatment). $B, A-582941(0.01,0.1$, and $1.0 \mu \mathrm{mol} / \mathrm{kg})$ was evaluated in the rat social recognition test, a model of short-term recognition memory. Adult rats, administered A-582941 intraperitoneally immediately after initial juvenile exposure (T1), produced a significant decrease in the duration of subsequent juvenile interaction (T2) $2 \mathrm{~h}$ later. Whereas vehicle-treated

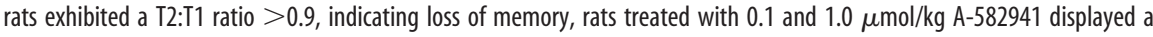
significantly lower ratio ( ${ }^{*} p<0.05$ vs vehicle-treated controls; $n=8$ per treatment). Data are represented as mean \pm SEM.

ing a titration paradigm, which has been described as being more sensitive to cognitive aging (Buccafusco et al., 2002). Treatment $30 \mathrm{~min}$ before testing with A-582941 (3, 10, and $30 \mathrm{nmol} / \mathrm{kg}$; i.m.) resulted in a significant improvement in task variables $\left(F_{(3,95)}=\right.$ 3.14; $p<0.05$ ) (Fig. $2 A$ ). Mean accuracy in the titrating task was significantly increased relative to vehicle treatment $(p<0.05)$. The increase in accuracy was accompanied by a significant increase in the maximal delay interval titrated $(p<0.05)$. Both parameters were statistically significant after administration of the $14 \mathrm{nmol} / \mathrm{kg}$ dose $(p<0.05)$. Accuracy increased by $10.2 \%$, and maximal delay increased by $36.5 \%$ relative to their respective vehicle means. The increase in maximal delay interval occurred 
A

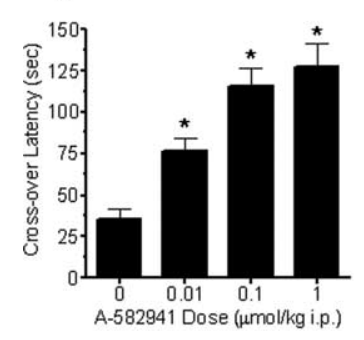

B

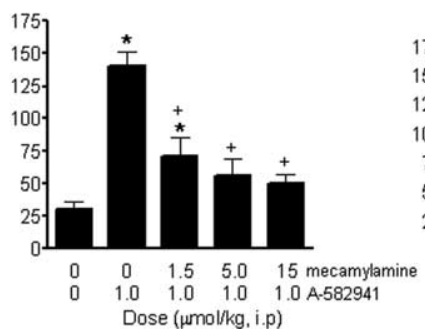

C

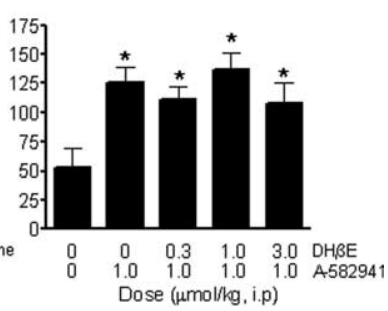

Figure 3. Efficacy profile in a long-term memory consolidation model. $A$, A-582941 $(0.01,0.1$, and $1.0 \mu \mathrm{mol} / \mathrm{kg})$ improved memory in the mouse inhibitory avoidance test, a model of long-term memory consolidation. Administered intraperitoneally 30 min before the training (shock) trial, A-582941 increased crossover latency during the test trial (no shock) $24 \mathrm{~h}$ later, an index of index of memory enhancement $\left({ }^{*} p<0.05\right.$ vs vehicle-treated control; $n=8-10$ per treatment). $\boldsymbol{B}$, Mecamylamine $(1.5,5$, and $15 \mu \mathrm{mol} / \mathrm{kg}$, i.p.) pretreatment (15 min) blocked inhibitory avoidance memory enhancement produced by A-582941 $(1.0 \mu \mathrm{mol} /$ $\mathrm{kg}$, i.p.) $\left({ }^{*} p<0.05\right.$ vs vehicle-treated control; ${ }^{+} p<0.05$ vs A-582941-alone-treated; $n=8-10$ per treatment). C, However, selective $\alpha 4 \beta 2 \mathrm{nAChR}$ antagonism by $\mathrm{DH} \beta \mathrm{E}(0.3,1.0$, and $3.0 \mu \mathrm{mol} / \mathrm{kg})$ did not block inhibitory avoidance memory enhancement produced by A-582941 (1.0 $\mu \mathrm{mol} / \mathrm{kg}$, i.p.) ( ${ }^{*} p<0.05$ vs vehicle-treated control; $n=8-10$ per treatment). Data are represented as mean \pm SEM.
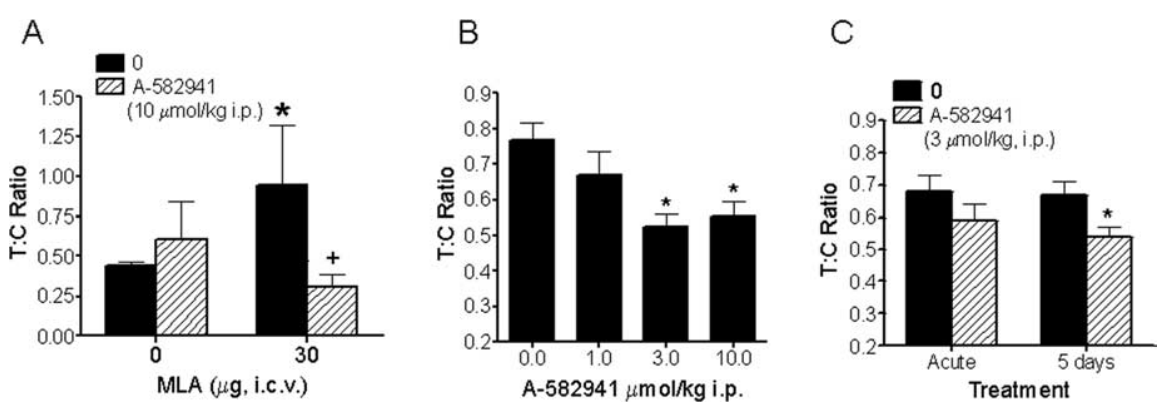

Figure 4. Efficacy profile in sensory gating/preattention. A, A-582941 improves N40 auditory-evoked sensory gating in rats in a model of $\alpha 7$-mediated preattention. A-582941 (10 $\mu \mathrm{mol} / \mathrm{kg}$, i.p.) reversed the $\mathrm{N} 40$ auditory-evoked sensory gating deficit in rats produced by intracerebroventricular administration of the $\alpha 7 \mathrm{nAChR}$ anatgonist MLA (30 $\mu \mathrm{g})$. Whereas MLA alone increases the $\mathrm{T}: \mathrm{C}$ ratio, an index of impaired sensory gating, pretreatment with A-582941 completely reverses the $\mathrm{N} 40$ deficit, as evidenced by a reduced T:C ratio ( ${ }^{*} p<0.05$ vs vehicle-treated control; ${ }^{+} p<0.05$ vs MLA-treated control; $n=6$ per treatment). $\boldsymbol{B}$, A-582941 improved N40 auditory-evoked sensory gating in DBA/2 mice, a genetic model of impaired sensory gating. Specifically, A-582941 improved N40 auditory-evoked gating as evidenced by the reduced $\mathrm{T}: \mathrm{C}$ ratio $\left({ }^{*} p<0.05\right.$ vs vehicle-treated control; $n=$ 16 - 40 per treatment) $C$, Improved N40 sensory gating was observed after 5 d of daily dosing in DBA/2 mice, indicating a lack of tolerance development $\left({ }^{*} p<0.05\right.$ vs vehicle-treated control; $n=23$ per treatment). Data are represented as mean \pm SEM.

\section{Long-term memory consolidation}

To determine the effects of $\alpha 7 \mathrm{nAChR}$ agonism on long-term memory consolidation, A-582941 was evaluated in a mouse twotrial inhibitory avoidance test. A-582941, administered 30 min before a shock training trial, produced a significant dose-dependent $(0.01,0.1,1.0, \mu \mathrm{mol} / \mathrm{kg}$, i.p.) increase in crossover latency during a retention test trial, $24 \mathrm{~h}$ after training (Fig. 3A). The plasma concentration $\left(C_{\max }\right)$ associated with the 0.1 and $1.0 \mu \mathrm{mol} / \mathrm{kg}$ dose of A-582941 is 2.6 and $26 \mathrm{ng} / \mathrm{ml}$, respectively. The ability of A-582941 to increase crossover latency during the retention test is consistent with enhanced long-term memory consolidation. Pretreatment with the nonselective nAChR antagonist mecamylamine (1.5-15 $\mu \mathrm{mol} / \mathrm{kg}$, i.p.) attenuated A-582941-evoked increase in crossover latency (Fig. $3 B$ ), whereas pretreatment with the $\alpha 4 \beta 2$ antagonist dihydro- $\beta$-erythroidine hydrobromide $(\mathrm{DH} \beta \mathrm{E})(0.3-3.0 \mu \mathrm{mol} / \mathrm{kg}$, i.p.) did not have an effect (Fig. 3C). Collectively, these results indicate that effects of A-582941 are $\mathrm{nAChR}$ mediated and the lack of a role of $\alpha 4 \beta 2$ subtype in the observed efficacy is consistent with the in vitro subtype selectivity of the compound.

\section{Sensory gating}

To examine the role of the $\alpha 7 \mathrm{nAChR}$ agonism on a measure of preattention, the ability of A-582941 to improve N40 auditory-evoked sensory gating was examined. As described in Materials and Methods, the degree of N40 gating is reflected by the ratio between the test and condition response amplitudes, with a decreased $\mathrm{T}: \mathrm{C}$ ratio representing increased $\mathrm{N} 40$ gating. In the first study, we examined the efficacy of A-582941 to reverse $\alpha 7$ antagonist-induced gating deficits in adult

without a significant increase in the number of trials required to attain the maximal delay $\left(F_{(5,15)}=0.45 ; p>0.1\right)$. As determined in other animals dosed with A-582941 intramuscularly, a 10 $\mathrm{nmol} / \mathrm{kg}$ dose corresponds to a plasma concentration of $6 \mathrm{ng} / \mathrm{ml}$ (21 nM).

Efficacy of A-582941 was also assessed in the rat social recognition test, an assay of short-term recognition memory. Adult rats, administered A-582941 immediately after initial juvenile exposure (T1), displayed a significant decrease in the duration of subsequent juvenile interaction (T2) $2 \mathrm{~h}$ later, consistent with short-term memory improvement (Fig. 2B). Whereas vehicle-treated rats exhibited a T2:T1 ratio $>0.9$, rats treated with 0.1 and $1.0 \mu \mathrm{mol} / \mathrm{kg}$ A-582941 displayed a significantly lower ratio, $<0.75$. Immediately after the second trial, the adult rats were exposed to a new juvenile for a third 5 min exposure trial (T3). The T3:T1 ratios between vehicle- and A-582941-treated groups were not significantly different, $>0.9$ from all groups (data not shown). The plasma concentrations at these efficacious doses ranged from 5 to 50 $\mathrm{ng} / \mathrm{ml}$ or from 17 to $170 \mathrm{nM}$ (extrapolated from dosing a group of animals at $0.1 \mu \mathrm{mol} / \mathrm{kg}$, i.p., dose). rat (Fig. 4A). Whereas saline-vehicle controls exhibited a mean $\mathrm{T}: \mathrm{C}$ ratio of 0.4 , rats receiving a single intracerebroventricular injection of the $\alpha 7$ antagonist MLA (30 $\mu \mathrm{g}) 5 \mathrm{~min}$ before the N40 EEG recording (20 min duration) displayed a larger $\mathrm{T}$ : $\mathrm{C}$ ratio of 0.9 , indicating decreased or impaired N40 gating. In contrast, 5 min pretreatment with A-582941 (10 $\mu \mathrm{mol} / \mathrm{kg}$, i.p.) reversed the MLA-induced N40 gating impairment, evidenced by a mean T:C ratio of 0.3 . Rats that received only A-582941 showed T:C ratios comparable with vehicle-treated controls.

Next, the ability of A-582941 to improve sensory gating was examined in DBA/2 mice, an inbred strain known to display a genetic deficit in N40 gating as well as reduced $\alpha 7$ expression in the CA3 hippocampus (Adams et al., 2001). In a crossover design, N40 EEG CA3 hippocampal recordings were measured after administration of A-582941 (1, 3, $10 \mu \mathrm{mol} / \mathrm{kg}$, i.p.) or saline (Fig. $4 B)$. Whereas a $\mathrm{T}$ : $\mathrm{C}$ ratio $>0.6$ was observed with saline treatment, consistent with impaired N40 gating, A-582941 normalized this deficit as revealed by a significant reduction in $\mathrm{T}$ : $\mathrm{C}$ ratios at 3 and $10 \mu \mathrm{mol} / \mathrm{kg}$ intraperitoneally. Given the reported tachyphylaxis associated with nicotine in the N40 sensory gating par- 
adigm (Stevens and Wear, 1997), we also examined the effect of repeated administration on gating. DBA/2 mice receiving daily injections of A-582941 (3 $\mu \mathrm{mol} / \mathrm{kg}$, i.p.) for 5 consecutive days were tested immediately after A-582941 on day 1 (acute) and day 5 (Fig. $4 C$ ). A reduction in the T:C ratio was observed on day 1 , consistent with deficit normalization as described above. A significant reduction in the $\mathrm{T}: \mathrm{C}$ ratio was also observed after $5 \mathrm{~d}$ of repeated administration. The fact that the normalization of the gating deficit by A-582941 was somewhat enhanced after $5 \mathrm{~d}$ of dosing suggests that the efficacy profile of selective $\alpha 7$ agonism is maintained with repeated dosing.

Potential mechanisms underlying $\alpha 7$ nAChR-mediated cognitive efficacy To examine potential mechanisms by which $\alpha 7$ agonism may be involved in mediating procognitive activity, the effects of A-582941 on signaling pathways known to be involved in cognitive function were examined. MAPK plays a critical role in several forms of neuroplasticity including memory formation (Adams and Sweatt, 2002) and neuronal survival (Heerssen and Segal, 2002). Activation of MAPK is required for memory consolidation because it mediates activity-dependent, $\mathrm{Ca}^{2+}$ stimulation of cAMP response element-mediated transcription. The ability of A-582941 to influence the ERK1/2MAPK pathway and CREB were examined both in vitro and in vivo.

\section{A-582941 increases ERK1/2}

\section{phosphorylation via $\alpha 7 \mathrm{nAChRs}$}

Stimulation of ERK1/2 phosphorylation in rat PC12 cells was used to determine activation of native $\alpha 7 \mathrm{nAChR}$. A-582941 increased ERK1/2 phosphorylation, which was attenuated when coincubated with 50 nM MLA (Fig. 5A). As shown in Figure 5B, the effects were concentration dependent $\left(\mathrm{EC}_{50}=95 \mathrm{nM} ; 95 \%\right.$ c.i., $81-111 \mathrm{~nm} ; n=3$ ).

Next, the effects on ERK1/2 phosphorylation were assessed in mouse prefrontal (cingulate) cortex and hippocampus, regions well recognized as anatomical substrates of cognition (Miyashita, 2004). As shown in Figure $5 C$, administration of A-582941 (0.01-1 $\mu \mathrm{mol} / \mathrm{kg}$, i.p., $15 \mathrm{~min}$ after administration) produced a dose-dependent increase in ERK1/2 phosphorylation in the cingulate cortex and hippocampus (dentate gyrus) as determined immunohistochemically using a phosphospecific $\mathrm{Ab}$ against the phosphorylated (i.e., activated) form of ERK1/2. In addition to the observed increase, the distribution of pERK1/2 expression in both the cingulate cortex and hippocampus of A-582941-treated mice was distinct compared with controls. Whereas the majority of pERK1/2 immunoreactivity was confined to the cell body of vehicle-treated mice, there appeared to be specific immunostaining in the neuronal processes of A-582941-treated mice in addition to somal pERK1/2 expression. As a negative control, omission of the primary $\mathrm{pERK} 1 / 2 \mathrm{Ab}$ resulted in a complete loss of immunostaining (data not shown). The significant increases in ERK1/2 phosphorylation observed at the 0.1 and $1.0 \mu \mathrm{mol} / \mathrm{kg}$ doses parallel the behavioral efficacy measured in the inhibitory avoidance model (Fig. 3A).

\section{Role of CREB phosphorylation}

In addition to ERK1/2 phosphorylation, studies were conducted to determine the effects of A-592941 on CREB phosphorylation (Fig. 6). Similar to ERK1/2, increased CREB phosphorylation was observed in the mouse cingulate cortex after administration of A-582941 (0.01, 0.1, $1.0 \mu \mathrm{mol} / \mathrm{kg}$ i.p., $15 \mathrm{~min}$ after administration). In contrast to pERK distribution, pCREB immunoreactivity was limited primarily to the nucleus, in which CREB is constitutively expressed. Similar to pERK, the dose-dependent increase in CREB phosphorylation was observed at behaviorally efficacious doses. As a negative control, omission of the primary $\mathrm{pCREB} \mathrm{Ab}$ resulted in a complete loss of immunostaining (data not shown).

\section{Pharmacological analysis of ERK-CREB signaling}

Studies were conducted to further validate $\alpha 7$ agonism-mediated MAPK activation by examining the effects of the MEK inhibitor SL327 on A-582941-induced ERK1/2 and CREB phosphorylation (Fig. 7). In a two-by-two design, pretreatment with SL327 (300 $\mu \mathrm{mol} / \mathrm{kg}$, i.p.) blocked the ability of A-582941 ( $1 \mu \mathrm{mol} / \mathrm{kg}$, i.p.) to increase ERK1/2 phosphorylation in the cingulate cortex. 
A
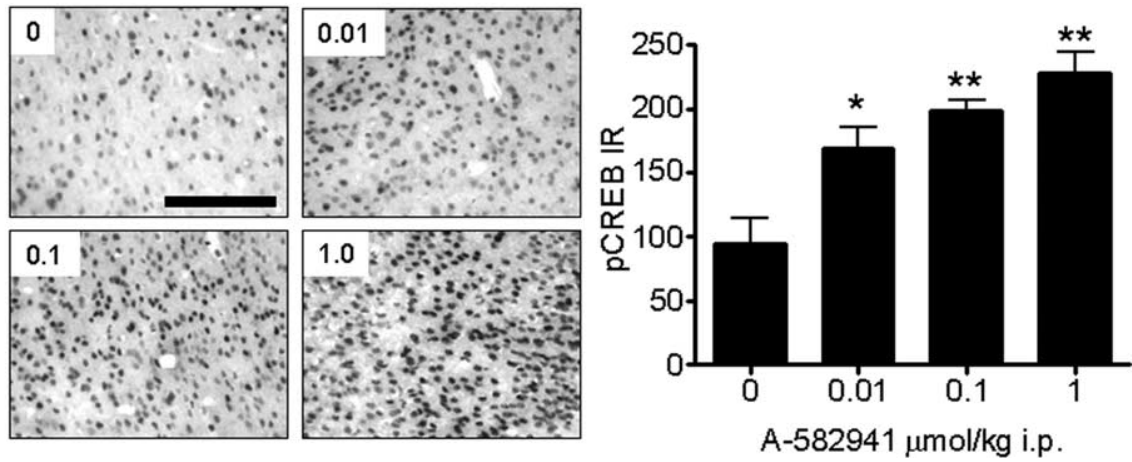

Figure 6. Effects on CREB phosphorylation in vivo. $A, B, A-582941(0.01,0.1$, and $1.0 \mu \mathrm{mol} / \mathrm{kg})$ increased phosphorylation of the transcription factor CREB in mouse cingulate cortex at behaviorally efficacious doses (15-20 min after injection; ${ }^{*} p<0.05$; ${ }^{* *} p<0.01$ vs vehicle-treated control; $n=6$ per treatment). Data are represented as mean \pm SEM. Scale bar, $150 \mu \mathrm{m}$.
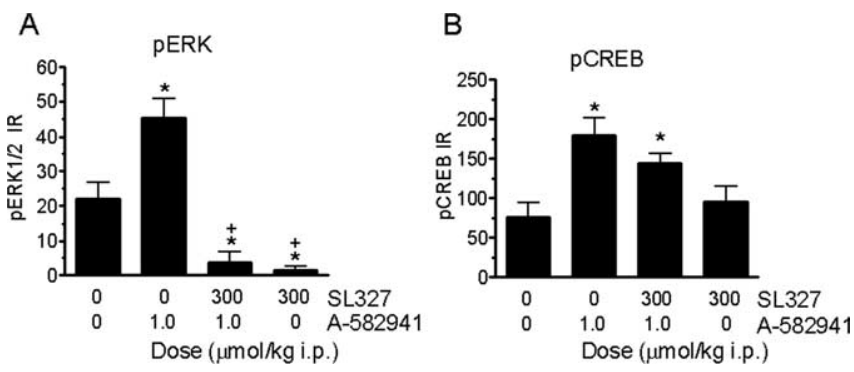

Figure 7. Influence of MEK inhibition on ERK1/2 and CREB phosphorylation in vivo. $A$, MEK inhibitor SL327 (300 $\mu \mathrm{mol} / \mathrm{kg}$, i.p.) pretreatment (15 min) blocked A-582941 (1.0)-induced and basal (tonic) ERK1/2 phosphorylation in mouse cingulate cortex $\left({ }^{*} p<0.05\right.$ vs nontreated control; ${ }^{+} p<0.05$ vs A-582941 alone; $n=6$ per treatment). B, MEK inhibitor SL327 (300 $\mu \mathrm{mol} / \mathrm{kg}$, i.p.) pretreatment (15 min) only produced a partial nonsignificant attenuation of A-582941-induced CREB phosphorylation, suggesting that other non-MAPK pathways may be involved in $\alpha 7$ agonism-mediated CREB phosphorylation ( ${ }^{*} p<0.01$ vs vehicle-treated controls). Data are represented as mean \pm SEM.

Interestingly, the SL327/A-582941 combination group exhibited a significant decrease in ERK1/2 phosphorylation compared with saline-treated controls (Fig. 7A). A similar reduction in basal ERK1/2 phosphorylation was also observed with SL327 alone, suggesting tonic MAPK activation under basal conditions. At the level of pCREB, SL327 pretreatment partially attenuated A-582941-induced CREB phosphorylation, although this did not achieve statistical significance (Fig. 7B). SL-327 alone, however, had no effects on CREB phosphorylation when compared with vehicle-treated controls.

\section{Discussion}

The molecular sequence of the $\alpha 7 \mathrm{nAChR}$ was determined over 15 years ago (Couturier et al., 1990), and although this major CNS nicotinic subtype has been implicated in cognitive function both physiologically and pathologically, only in the last few years have selective agonists (Van Kampen et al., 2004; Hajos et al., 2005; Pichat et al., 2007) been described in learning and memory paradigms demonstrating potential utility for treating cognitive dysfunction. Results presented here provide a comprehensive examination of a novel $\alpha 7$ agonist, A-582941, across a battery of behavioral assays representing different "domains" of cognition that included short-term memory, long-term memory consolidation, and preattentional sensory gating. Additionally, we examined the effects of $\alpha 7 \mathrm{nAChR}$ agonism on cellular signaling involving cognition-associated pathways, specifi- cally MAPK and CREB phosphorylation. Pharmacologically, A-582941 represented a highly CNS penetrant ligand with low nanomolar affinity to native rat and human $\alpha 7$ nAChRs, displaying similar agonist activation in rat and human recombinant $\alpha 7$ expression systems. Our present study demonstrates that $\alpha 7 \mathrm{nAChR}$ agonism can elicit broad-spectrum efficacy across various $\operatorname{cog}$ nitive domains. Furthermore, results presented here represent the first description of cognitive-related signaling in vivo by a selective $\alpha 7$ agonist at doses (i.e., drug plasma exposure levels) known to produce cognition enhancement.

A predominant cognitive deficit observed in $\mathrm{AD}$ is the initial loss of shortterm memory (Germano and Kinsella, 2005). A-582941 improved performance in both the monkey DMTS and rat social recognition tests, cognitive measures that represent domains of working and shortterm recognition memory, respectively. In DMTS-trained monkeys, A-582941 increased accuracy and extended the delay interval over which the monkeys could remember the target stimulus during each trial, consistent with working, (i.e., "trialdependent”) memory improvement. Similarly, A-582941 improved recognition memory in adult rats as measured by a reduction in interactive behavior when reintroduced to a juvenile rat $2 \mathrm{~h}$ later, an index of enhanced short-term memory processing. Short-term memory in general, particularly working memory, is regarded to be highly dependent on the prefrontal cingulate cortex (Dalley et al., 2004) in which A-582941 increased both ERK and CREB phophorylation (vide infra).

Transformation of short- to long-term memory consolidation represents a cognitive domain that can be examined in behavioral models involving aversive stimulus conditions, such as two-trial inhibitory avoidance conditioning. Long-term memory consolidation after a single learning trial has been shown to be dependent on hippocampal nAChR activation (Marti Barros et al., 2004). When administered before training, pairing footshock with entry into a dark compartment, A-582941 increased subsequent ( $24 \mathrm{~h}$ ) entry into the dark compartment, consistent with improved memory consolidation. Mecamylamine, but not $\mathrm{DH} \beta \mathrm{E}$, pretreatment prevented the enhancement of inhibitory avoidance acquisition. Whereas mecamylamine is a nonselective $\mathrm{nAChR}$ blocker, $\mathrm{DH} \beta \mathrm{E}$ selectively antagonizes the $\alpha 4 \beta 2$ subtype. Because $\alpha 7$ and $\alpha 4 \beta 2 \mathrm{nAChRs}$ have both been implicated in cognitive function and are considered the two predominant native subtypes in brain, the block of efficacy by mecamylamine, but not $\mathrm{DH} \beta \mathrm{E}$, supports an $\alpha 7 \mathrm{nAChR}-$ mediated effect in the inhibitory avoidance model.

In addition to cognitive measures associated with learning and memory, the effects of $\alpha 7 \mathrm{nAChR}$ agonism on EEG sensory gating deficits were assessed. Considered an index of preattentional cognitive processing, evoked EEG potentials in response to closely paired auditory stimuli represents a form of sensory gating that is observed in both rodents and humans, specifically referred to as N40 or P50 sensory gating, respectively. Normal N40/P50 sensory gating consists of an attenuation of the EEG amplitude evoked by the second (test) versus first (condition) auditory stimulus. Thus, N40/P50 impairment is reflected as an increase in the ratio of the test and condition (T:C) response. Clinically, deficits in P50 sensory gating have been observed in schizophrenia and $\mathrm{AD}$, both disorders linked to the $\alpha 7$ nAChR (Freedman et al., 2000; Court et al., 2001). As reported 
here, intracerebroventricular administration of the $\alpha 7 \mathrm{nAChR}$ antagonist MLA in Sprague Dawley rats produced a deficit in N40 gating, further supporting the contribution of the $\alpha 7 \mathrm{nAChR}$ in sensory gating. Moreover, the ability of A-582941 to prevent the MLA-induced N40 deficit supports a specific $\alpha 7 \mathrm{nAChR}$-mediated action, which is consistent with the in vitro observation of MLA inhibition of A-582941-evoked pERK expression (see below).

The inability to adequately treat the cognitive deficits associated with schizophrenia with dopaminergic- and serotoninergic-based antipsychotic agents has placed a medical need for identifying new pharmacological targets such as the $\alpha 7 \mathrm{nAChR}$. In this regard, P50/ N40 sensory gating may provide a model for examining procognitive efficacy in schizophrenia through $\alpha 7 \mathrm{nAChR}$ agonism. The $\alpha 7$ nAChR agonist PNU-282987 was previously shown to reverse amphetamine-induced N40 deficit in rats (Hajos et al., 2005), and GTS-21, which interacts with both $\alpha 7$ and $\alpha 4 \beta 2 \mathrm{nAChRs,} \mathrm{was}$ shown to be effective in DBA/2 mice, an inbred strain known to exhibit N40 sensory gating deficits and reduced $\alpha 7 \mathrm{nAChR}$ expression similar to schizophrenic patients (Stevens et al., 1998; Adams et al., 2001). Because the role of $\alpha 7 \mathrm{nAChRs}$ in mediating the psychotomimetic action of amphetamine has not been addressed directly, we examined the effects of A-582941 on hippocampal sensory gating in the DBA/2 mouse N40 model and found that acute administration of A-582941 normalized the N40 deficit. Furthermore, repeated administration of A-582941 did not result in a loss of efficacy. Indeed, the gating normalization observed after $5 \mathrm{~d}$ of daily dosing was somewhat superior versus the acute (i.e., day 1) effect, suggesting that the $\alpha 7 \mathrm{nAChR}$ agonism produced by A-582941 does not lead to tolerance with subacute dosing. Although nicotine has been reported to improve $\mathrm{N} 40$ gating in $\mathrm{DBA} / 2$ mice, it is associated with a loss of efficacy with repeated same-day dosing thought to result from tachyphylaxis (Stevens and Wear, 1997).

Comparisons of plasma levels for efficacy across models show that maximal efficacy can be achieved close to $10 \mathrm{nM}(2 \mathrm{ng} / \mathrm{ml}$ or 5.7 $\mathrm{nM}$ in monkey DMTS, $5 \mathrm{ng} / \mathrm{ml}$ or $17 \mathrm{nM}$ in rat short-term recognition, and $2.6 \mathrm{ng} / \mathrm{ml}$ or $7 \mathrm{~nm}$ in mouse memory consolidation models). This is in the range of the $\alpha 7$-binding $K_{\mathrm{i}}$ value but, interestingly, below levels associated with ionotropic function (as measured by electrophysiology). This suggests that minimal receptor activation is sufficient for triggering procognitive effects. Unlike other nAChRs, the $\alpha 7$ subtype is highly permeant to calcium such that part of its signal, perhaps the more important signal, may be metabotropic in nature, triggered by calcium influx. Our observation that intracellular events initiated by $\alpha 7$ receptor activation may require low levels of receptor stimulation has important ramification in disease states such as schizophrenia, in which $\alpha 7$ agonist-mediated signaling would be expected despite reduced $\alpha 7 \mathrm{nAChR}$ expression (Freedman et al., 2000).

In addition to behavioral assessment of A-582941, studies were conducted to investigate the cellular signaling that may contribute to the procognitive efficacy associated with $\alpha 7 \mathrm{nAChR}$ agonism. Given the higher calcium permeability associated with $\alpha 7 \mathrm{nAChRs,} \mathrm{we}$ speculated that agonist stimulation activates calcium-dependent signal transduction pathways implicated in cognition. The MAPKERK pathway regulates a diverse array of cellular functions, such as cell growth, differentiation, and survival, that may underlie the synaptic plasticity required for cognitive processing and memory formation (Adams and Sweatt, 2002; Giovannini, 2006). Although the involvement of $\alpha 7 \mathrm{nAChRs}$ in activating signaling pathways such as ERK and CREB have previously been described, these studies have primarily involved the use of nicotine in which activation of ERK1/2 in neuroblastoma and cultured hippocampal cells (Dajas-Bailador et al., 2002) and CREB in PC12 cells (Nakayama et al., 2001) has been reported. However, these results suggest that the use of nicotine to examine the effects of $\alpha 7$ agonism on signaling pathways may be hampered by issues of both nonselectively and receptor desensitization.

Our studies demonstrated that $\alpha 7 \mathrm{nAChR}$ agonism produced by A-582941 activated ERK1/2 and CREB signaling in vitro and in vivo. In PC12 cells that endogenously express $\alpha 7 \mathrm{nAChRs,} \mathrm{agonist-evoked}$ ERK1/2 phosphorylation was attenuated by MLA. In mice, A-582941 at doses within the range required for cognition efficacy (plasma concentrations, $1-30 \mathrm{ng} / \mathrm{ml}$ ) increased ERK1/2 phosphorylation in the cingulate cortex and hippocampus. Both of these telencephalic regions exhibit high $\alpha 7 \mathrm{nAChR}$ expression (Seguela et al., 1993) and are recognized as anatomical substrates of learning and memory (Miyashita, 2004). The MEK inhibitor SL327 prevented A-582941-induced ERK1/2 phosphorylation, suggesting that increased pERK1/2 immunoreactivity after A-582941 is mediated in part through the ERK-MAPK pathway. Interestingly, the level of ERK phosphorylation observed in the SL327-alone group was significantly lower than the vehicle-treated controls, suggesting that basal ERK phosphorylation in the cingulate cortex is tonically activated. Such tonic regulation may be important in cognitive function in general, because SL327 has been shown to block contextual fear conditioning and spatial learning in mice (Selcher et al., 1999).

A-582941 also increased CREB Ser-133 phosphorylation in the cingulate cortex in a dose-dependent manner. Functioning as a transcription factor after Ser-133 phosphorylation, CREB is a downstream substrate and effector of various signal transduction pathways, including ERK (Carlezon et al., 2005). In this regard, CREB phosphorylation represents a common downstream link involving multiple signaling pathways initiated by membrane receptormediated actions to the cell nucleus, in which CREB phosphorylation induces gene transcription. CREB-mediated transcription involves gene changes responsible for the synaptic plasticity implicated in cognitive function that includes brain-derived neurotrophic factor, a neurotrophic factor required for neurite outgrowth (Ring et al., 2006). In contrast to the complete block of ERK1/2 phosphorylation, SL327 pretreatment in mice only partially attenuated A-582941-induced CREB phosphorylation. This finding suggests that independent of the MAPK-ERK pathway, $\alpha 7 \mathrm{nAChR}$ agonism can lead to activation of other calcium-dependent kinase pathways known to stimulate CREB phosphorylation, such as calmodulindependent kinase IV or protein kinase A, although additional studies need to be undertaken to further elucidate these mechanisms.

In summary, the novel $\alpha 7 \mathrm{nAChR}$ agonist A-582941 produced broad-spectrum efficacy across cognitive domains implicated in neurodegenerative and psychiatric disorders such as AD and schizophrenia. Furthermore, A-582941 at doses producing behavioral efficacy increased cortical and hippocampal cellular signaling associated with cognitive function (i.e., MAPK and CREB phosphorylation). Together, these results provide preclinical evidence suggesting that selective $\alpha 7 \mathrm{nAChR}$ agonism may translate to improved pharmacotherapy for treating cognitive disorders that may involve activation of MAPK- and CREB-linked pathways.

\section{References}

Adams CE, Stitzel JA, Collins AC, Freedman R (2001) Alpha7-nicotinic receptor expression and the anatomical organization of hippocampal interneurons. Brain Res 922:180-190.

Adams JP, Sweatt JD (2002) Molecular psychology: roles for the ERK MAP kinase cascade in memory. Annu Rev Pharmacol Toxicol 42:135-163.

Bartus RT (2000) On neurodegenerative diseases, models, and treatment strategies: lessons learned and lessons forgotten a generation following the cholinergic hypothesis. Exp Neurol 163:495-529. 
Berg DK, Conroy WG (2002) Nicotinic alpha 7 receptors: synaptic options and downstream signaling in neurons. J Neurobiol 53:512-523.

Biton B, Bergis OE, Galli F, Nedelec A, Lochead AW, Jegham S, Godet D, Lanneau C, Santamaria R, Chesney F, Leonardon J, Granger P, Debono MW, Bohme GA, Sgard F, Besnard F, Graham D, Coste A, Oblin A, Curet O, et al. (2007) SSR180711, a novel selective alpha7 nicotinic receptor partial agonist: (1) binding and functional profile. Neuropsychopharmacology 32:1-16.

Briggs CA, McKenna DG (1998) Activation and inhibition of the human alpha7 nicotinic acetylcholine receptor by agonists. Neuropharmacology 37:1095-1102.

Buccafusco JJ, Terry Jr AV, Murdoch PB (2002) A computer-assisted cognitive test battery for aged monkeys. J Mol Neurosci 19:179-185.

Carlezon Jr WA, Duman RS, Nestler EJ (2005) The many faces of CREB. Trends Neurosci 28:436-445.

Court J, Martin-Ruiz C, Piggott M, Spurden D, Griffiths M, Perry E (2001) Nicotinic receptor abnormalities in Alzheimer's disease. Biol Psychiatry 49:175-184.

Couturier S, Bertrand D, Matter JM, Hernandez MC, Bertrand S, Millar N, Valera S, Barkas T, Ballivet M (1990) A neuronal nicotinic acetylcholine receptor subunit (alpha 7) is developmentally regulated and forms a homo-oligomeric channel blocked by alpha-BTX. Neuron 5:847-856.

Curzon P, Anderson DJ, Nikkel AL, Fox GB, Gopalakrishnan M, Decker MW, Bitner RS (2006) Antisense knockdown of the rat alpha7 nicotinic acetylcholine receptor produces spatial memory impairment. Neurosci Lett 410:15-19.

Dajas-Bailador FA, Soliakov L, Wonnacott S (2002) Nicotine activates the extracellular signal-regulated kinase $1 / 2$ via the alpha7 nicotinic acetylcholine receptor and protein kinase A, in SH-SY5Y cells and hippocampal neurones. J Neurochem 80:520-530.

Dalley JW, Cardinal RN, Robbins TW (2004) Prefrontal executive and cognitive functions in rodents: neural and neurochemical substrates. Neurosci Biobehav Rev 28:771-784.

Favata MF, Horiuchi KY, Manos EJ, Daulerio AJ, Stradley DA, Feeser WS, Van Dyk DE, Pitts WJ, Earl RA, Hobbs F, Copeland RA, Magolda RL, Scherle PA, Trzaskos JM (1998) Identification of a novel inhibitor of mitogen-activated protein kinase kinase. J Biol Chem 273:18623-18632.

Fisher A, Pittel Z, Haring R, Bar-Ner N, Kliger-Spatz M, Natan N, Egozi I, Sonego H, Marcovitch I, Brandeis R (2003) M1 muscarinic agonists can modulate some of the hallmarks in Alzheimer's disease: implications in future therapy. J Mol Neurosci 20:349-356.

Freedman R, Adams CE, Leonard S (2000) The alpha7-nicotinic acetylcholine receptor and the pathology of hippocampal interneurons in schizophrenia. J Chem Neuroanat 20:299-306.

Gault J, Hopkins J, Berger R, Drebing C, Logel J, Walton C, Short M, Vianzon R, Olincy A, Ross RG, Adler LE, Freedman R, Leonard S (2003) Comparison of polymorphisms in the alpha7 nicotinic receptor gene and its partial duplication in schizophrenic and control subjects. Am J Med Genet B Neuropsychiatr Genet 123:39-49.

Germano C, Kinsella GJ (2005) Working memory and learning in early Alzheimer's disease. Neuropsychol Rev 15:1-10.

Giovannini MG (2006) The role of the extracellular signal-regulated kinase pathway in memory encoding. Rev Neurosci 17:619-634.

Gray R, Rajan AS, Radcliffe KA, Yakehiro M, Dani JA (1996) Hippocampal synaptic transmission enhanced by low concentrations of nicotine. Nature 383:713-716.

Hajos M, Hurst RS, Hoffmann WE, Krause M, Wall TM, Higdon NR, Groppi VE (2005) The selective alpha7 nicotinic acetylcholine receptor agonist PNU-282987 [N-[(3R)-1-azabicyclo[2.2.2] oct-3-yl]-4-chlorobenzamide hydrochloride] enhances GABAergic synaptic activity in brain slices and restores auditory gating deficits in anesthetized rats. J Pharmacol Exp Ther 312:1213-1222.

Harris JG, Kongs S, Allensworth D, Martin L, Tregellas J, Sullivan B, Zerbe G, Freedman R (2004) Effects of nicotine on cognitive deficits in schizophrenia. Neuropsychopharmacology 29:1378-1385.

Heerssen HM, Segal RA (2002) Location, location, location: a spatial view of neurotrophin signal transduction. Trends Neurosci 25:160-165.

Jessen F, Kucharski C, Fries T, Papassotiropoulos A, Hoenig K, Maier W, Heun R (2001) Sensory gating deficit expressed by a disturbed suppression of the P50 event-related potential in patients with Alzheimer's disease. Am J Psychiatry 158:1319-1321.
Kasa P, Rakonczay Z, Gulya K (1997) The cholinergic system in Alzheimer's disease. Prog Neurobiol 52:511-535.

Levin ED, Simon BB (1998) Nicotinic acetylcholine involvement in cognitive function in animals. Psychopharmacology (Berl) 138:217-230.

Levin ED, McClernon FJ, Rezvani AH (2006) Nicotinic effects on cognitive function: behavioral characterization, pharmacological specification, and anatomic localization. Psychopharmacology (Berl) 184:523-539.

Marti Barros D, Ramirez MR, Dos Reis EA, Izquierdo I (2004) Participation of hippocampal nicotinic receptors in acquisition, consolidation and retrieval of memory for one trial inhibitory avoidance in rats. Neuroscience 126:651-656.

Miyashita Y (2004) Cognitive memory: cellular and network machineries and their top-down control. Science 306:435-440.

Nakayama H, Numakawa T, Ikeuchi T, Hatanaka H (2001) Nicotineinduced phosphorylation of extracellular signal-regulated protein kinase and CREB in PC12h cells. J Neurochem 79:489-498.

Nordberg A (2001) Nicotinic receptor abnormalities of Alzheimer's disease: therapeutic implications. Biol Psychiatry 49:200-210.

Pabreza LA, Dhawan S, Kellar KJ (1991) [3H]cytisine binding to nicotinic cholinergic receptors in brain. Mol Pharmacol 39:9-12.

Pichat P, Bergis OE, Terranova JP, Urani A, Duarte C, Santucci V, Gueudet C, Voltz C, Steinberg R, Stemmelin J, Oury-Donat F, Avenet P, Griebel G, Scatton B (2007) SSR180711, a novel selective alpha7 nicotinic receptor partial agonist: (II) efficacy in experimental models predictive of activity against cognitive symptoms of schizophrenia. Neuropsychopharmacology 32:17-34.

Potter A, Corwin J, Lang J, Piasecki M, Lenox R, Newhouse PA (1999) Acute effects of the selective cholinergic channel activator (nicotinic agonist) ABT-418 in Alzheimer's disease. Psychopharmacology (Berl) 142:334-342.

Radcliffe KA, Fisher JL, Gray R, Dani JA (1999) Nicotinic modulation of glutamate and GABA synaptic transmission of hippocampal neurons. Ann NY Acad Sci 868:591-610.

Rezvani AH, Levin ED (2001) Cognitive effects of nicotine. Biol Psychiatry 49:258-267.

Ring RH, Alder J, Fennell M, Kouranova E, Black IB, Thakker-Varia S (2006) Transcriptional profiling of brain-derived-neurotrophic factor-induced neuronal plasticity: a novel role for nociceptin in hippocampal neurite outgrowth. J Neurobiol 66:361-377.

Seguela P, Wadiche J, Dineley-Miller K, Dani JA, Patrick JW (1993) Molecular cloning, functional properties, and distribution of rat brain $\alpha 7$ : a nicotinic cation channel highly permeable to calcium. J Neurosci 13:596-604.

Selcher JC, Atkins CM, Trzaskos JM, Paylor R, Sweatt JD (1999) A necessity for MAP kinase activation in mammalian spatial learning. Learn Mem 6:478-490.

Stassen HH, Bridler R, Hagele S, Hergersberg M, Mehmann B, Schinzel A, Weisbrod M, Scharfetter C (2000) Schizophrenia and smoking: evidence for a common neurobiological basis? Am J Med Genet 96:173-177.

Stevens KE, Wear KD (1997) Normalizing effects of nicotine and a novel nicotinic agonist on hippocampal auditory gating in two animal models. Pharmacol Biochem Behav 57:869-874.

Stevens KE, Kem WR, Mahnir VM, Freedman R (1998) Selective alpha7nicotinic agonists normalize inhibition of auditory response in DBA mice. Psychopharmacology (Berl) 136:320-327.

Trumbull JD, Maslana ES, McKenna DG, Nemcek TA, Niforatos W, Pan JY, Parihar AS, Shieh CC, Wilkins JA, Briggs CA, Bertrand D (2003) High throughput electrophysiology using a fully automated, multiplexed recording system. Receptors Channels 9:19-28.

Van Kampen M, Selbach K, Schneider R, Schiegel E, Boess F, Schreiber R (2004) AR-R 17779 improves social recognition in rats by activation of nicotinic alpha7 receptors. Psychopharmacology (Berl) 172:375-383.

White HK, Levin ED (1999) Four-week nicotine skin patch treatment effects on cognitive performance in Alzheimer's disease. Psychopharmacology (Berl) 143:158-165.

Yu WF, Guan ZZ, Bogdanovic N, Nordberg A (2005) High selective expression of alpha7 nicotinic receptors on astrocytes in the brains of patients with sporadic Alzheimer's disease and patients carrying Swedish APP 670/671 mutation: a possible association with neuritic plaques. Exp Neurol 192:215-225. 